\title{
0 terceiro, comum e comunicável para a plenitude e liberdade: aspectos da pneumatologia de Joseph Moingt
}

\author{
The third, common and communicable for the fullness and \\ freedom: aspects of the pneumatology by Joseph Moingt
}

\section{Roberto Nentwig*}

Pontifícia Universidade Católica do Rio de Janeiro, Rio de Janeiro, RJ, Brasil

\section{Resumo}

Este artigo traz alguns aspectos da pneumatologia de Moingt, que trata do Espírito Santo na dinâmica trinitária. Para o autor, Deus é uma existência pluripessoal: somente pode se comunicar, porque é trinitário; um Deus monolítico seria uma solidão incomunicável. O Pai e o Filho são um, comunhão possibilitada pelo Espírito, nomeado como o terceiro porque se coloca na relação entre o primeiro e o segundo, realizando o deslocamento do eu para nós. Este terceiro é um ser comum e comunicável: é comum a Cristo e ao Pai e comunicável a todas as criaturas por intermédio do Filho, agindo na história, que está grávida da presença salvífica de Cristo, até que o mundo seja a imagem divina, quando seremos tudo em todos - comunhão universal. Este mesmo Espírito é chamado de "espírito de Cristo" (Rm 8,9) e espírito de liberdade: a mesma liberdade de Cristo Jesus é agora transferida ao mundo e a Igreja. A Igreja, portadora do Espírito de Cristo, será dócil a esta presença à medida que deixar seu enrijecimento

"RN: Doutor em Teologia, e-mail: beto.catequese@gmail.com 
institucional, além de promover a comunhão das pluralidades até o dia da comunhão universal, que está em processo de gestação na história.

Palavras-chave: Espírito Santo. Comum. Comunicável. Plenitude. Liberdade.

\section{Abstract}

This article is composed of some aspects of the pneumatology by Moingt, which deals with the Holy Ghost as in the trinitarian dynamics. For the author, God is a pluripersonal existence: He can only communicate because He is trinitarian; a monolithic God would stand as an incommunicable solitude of existence. The Father and The Son are one, a communion made possible by the Spirit, named as the Third for His correct relationship between the First and the Second, performing the displacement from the Me to the Us. This third is a common and communicable being: He is common to Christ and to the Father - and - communicable to every creature by the mediation of the Son, performing into the history which is pregnant with the salvific presence of Christ, until the world is the Divine Image, when we will stand as all in everyone, a universal communion then. This Spirit is called Himself "Christ's Spirit" (Rom 8,9) and Spirit of freedom: the performing liberty of Christ-Jesus is now transferred to the world and the Church. The Church, as the bearer of the Spirit of Christ, will be gentle to this presence as it abandons its institutional stiffening, besides promoting the communion of pluralities until the day of the universal communion that finds itself (as for now) in a conducting process through history.

Keywords: The Holy Ghost. Common. Communicable. Fullness. Freedom.

\section{Introdução}

Joseph Moingt, jesuíta francês, é um teólogo de grande envergadura. Foi professor de L'Institut Cathólique de Paris e Centre Sèvres, tendo dirigido a revista Recherches de Science Religieuse. Já tendo ultrapassado a 
casa dos cem anos, ainda está em atividade e tem grande reconhecimento, sobretudo na Europa. O Brasil ainda está descobrindo este gênio.

Este artigo traz alguns aspectos da pneumatologia de Moingt. O Espírito Santo certamente terá que ser entendido a partir de sua teologia sobre a Trindade, conectada à economia salvífica. Neste sentido, dois pressupostos da teologia de Moingt são fundamentais para entendermos as linhas que se seguem: a processualidade e a relação com a filosofia da intersubjetividade.

A teologia de nosso teólogo francês é processual. Segue a linha que concebe o Universo como um processo evolutivo: sem excluir as tentativas fracassadas e o acaso, pensa-se que o cosmos tende a se organizar para vias mais complexas cada vez mais, guiado por um princípio de inteligibilidade, sem com isso defender um finalismo absoluto. O universo está em projeção de ser, e também Deus, de algum modo, que segue em comunhão com a obra criadora na história, insere-se nesta mesma projeção.

Um segundo pressuposto é a filosofia da intersubjetividade, base para entender a sua Trindade Econômica. Primeiramente, com uma conotação de pensamento próxima de Lévinas, Moingt entende que o conceito eu-tu pode ser adequado ao pensamento cristão (LÉVINAS, 1982). Nesta linha, a relação entre Deus e a criação é realizada por um ser-totalmente-no-outro que não elimina o ser-em-si-mesmo: não há somente um eu e um tu, mas também um nós. O ser humano se descobre na relação com o tu, mas encontra o seu lugar próprio na história do Povo de Deus, na nossa história. Por isso, não é um simples eu, mas um nós. Moingt, neste âmbito de pensamento, realiza frutuoso diálogo com a filosofia de Merleau-Ponty que, por sua vez, entende a pessoa como uma subjetividade aberta, identificada com a presença no mundo, diante dos outros: não existe um ser em si, mas um ser-para-si que se define em seu ser-no-mundo (MERLEAU-PONTY, 1975, p. 493-612).

Moingt se insere dentro deste horizonte dialogal, intersubjetivo. É neste horizonte que entenderemos a sua pneumatologia. Primeiramente veremos que o Espírito se insere no diálogo mútuo das pessoas divinas (existência pluripessoal). Depois, veremos a abertura deste diálogo intersubjetivo ao mundo e a nós, que se dá pela comunicação do Espírito, 
aquele que encaminha o projeto divino à plenitude. Por fim, trataremos do Espírito como Espírito de liberdade, tema muito caro para o autor francês.

\section{Deus: uma existência pluripessoal}

Deus não está só, não é um ser monolítico, mas revela uma existência pluripessoal (MOINGT, 2010b, p. 319). O Cristianismo venceu a tentação de procurar salvar o monoteísmo tão arraigado no judaísmo, declarando na formulação do Credo primitivo o Deus-Trindade, apesar de constatarmos ainda em teólogos contemporâneos o medo do risco de comprometer a unicidade de Deus (MOINGT, 2014, p. 477-478). Deus é um ser em relação (esse ad) que vem ao mundo por seu Verbo e por seu Espírito, uma relação imanente e exteriorizada que se desdobra de modo eterno e indestrutível pelo elo entre o Pai e o seu Filho (MOINGT, 2014, p. 490). Se, como demonstra a psicologia, nós fazemos nossa identidade nos fechando, ou seja, individualizando-nos, Deus é uma relação de pessoas que se abrem ao máximo, que subsistem um no outro.

Tal inter-relação já estava prenunciada na criação do ser humano, quando se proclama a palavra criadora "Façamos o homem à nossa imagem e semelhança” (Gn 1,26). No Evangelho esta relação será amplamente revelada, como nos afirma Jesus: "Não estou só, porque o Pai está comigo" (Jo 16,32). Tal relação pluripessoal se abre ao ser humano, pois este foi escolhido por Deus "desde a fundação no mundo" (Ef 1,4) (MOINGT, 2010b, p. 154; 157).

O Deus Trindade visita e se relaciona com o ser humano, como se revela na visita dos três misteriosos homens a Abraão no Carvalho de Mambré, que na visão dos Santos Padres é uma teofania reveladora da Trindade. Portanto, é esta pluri-relação que vem ao encontro do ser humano na história, os três visitadores (MOINGT, 1999) que participam da hospitalidade humana. O ser humano é convidado a viver sua vocação relacional e pluripessoal com os outros, com a criação e com Deus. Deus, por sua vez, somente pode se comunicar, porque é trinitário; um Deus monolítico seria uma solidão incomunicável (MOINGT, 2014, p. 478). 
Moingt elabora a sua teologia trinitária na história, jamais numa existência imanente, partindo da radicalidade do axioma rahneriano (MOINGT, 2008b, p. 218; 220; MOINGT, 2014, p. 452-453). Nesta linha, Deus se revela em sua doação na história, jamais em um dogma ou existência eternal; revela-se em sua história de amor que tem o seu grande momento na humanização de Deus (MOINGT, 2008b, p. 586). Nas duas grandes teofanias trinitárias (Mc 1,11; Mc 9,7), o Pai é um ser falante, enquanto o Filho escuta a sua palavra, ficando o Espírito Santo presente como alguém que estabelece um elo entre os outros dois. É o Espírito que faz o Filho ouvir e sentir a voz declarada do Pai que o proclama Filho, confirmação de que o Filho é a palavra do Pai, palavra de vida (MOINGT, 2014, p. 477). O Pai não se nomeia, mas pelo elo de comunicação do Espírito, é o Filho que o declara: "o Pai falando pela boca do Filho, o Filho lendo o que o Pai escreve nele, o Espírito transcrevendo no coração dos discípulos o diálogo silencioso, tecido por ele mesmo, do Pai e do Filho" (MOINGT, 2010b, p. 152).

Portanto, na boca de Jesus, Deus é revelado como pai. Trata-se de um Deus próximo, bom, dessacralizado que está perto de todos e em qualquer lugar. Jesus tem um modo singular de se relacionar com o Pai: chama-o de meu Pai e nomeia a si mesmo como filho (MOINGT, 2010a, p. 290-291). O Pai (apelante) dirige-se ao Filho (respondente), aquele que tem a capacidade de dizer tu ao Pai. O respondente revela o Pai. Na resposta do Filho ao Pai não está apenas uma palavra singular, mas abre-se ao plural, de modo a incluir a todos: "o nós é um eu difundido e ampliado" (MOINGT, 2010b, p. 153). O nós do Filho é uma ampliação que convida a uma comunhão universal, como vemos na oração de Jesus ao Pai, rogando para que os seus discípulos permaneçam unidos entre eles, "a fim de que todos sejam um" (Jo 17,21) como o Pai e o Filho são um. Quem possibilita esta comunhão é o Espírito, nomeado como o terceiro, não por ser menos importante entre os três, mas porque se coloca na relação entre o primeiro e o segundo, possibilitando o deslocamento do eu para nós. O eu precisa se desapropriar de si mesmo em favor do nós (por isso, rezamos: Pai nosso, e não Pai meu). O Espírito é o terceiro no sentido de que é aquele que completa a trindade, que impede que ela seja reduzida a uma solidão. $\mathrm{O}$ terceiro estabelece uma relação pluripessoal de alteridade, ao estar entre 
o Filho e o Pai. É o excesso de amor que se abre e se derrama no mundo em superabundância (MOINGT, 2003, p. 319-325).

Moingt considera que a revelação intersubjetiva da Trindade está na cruz, pois não é possível narrar a história de Jesus sem falar da história entre o Filho e o Pai, e tal relação tem sua expressão máxima na morte de Cristo. Nela, o Filho se entrega em sua obediência ao Pai, no Espírito. Na cruz o Filho expressa o seu sim - a resposta plena a aquele que acolhe a sua voz, a resposta ao apelo divino que está inscrito em seu ser, descoberto como projeto do Pai ao longo de sua existência humanizada, que se resume na consciência da necessidade da oferta de seu ser. A cruz, no entanto, não é um ato isolado, nem da vida de Jesus, nem da sua ressurreição e nem da processão do Espírito. Pelo mistério pascal, a Trindade revela a processão do Espírito do Pai ao Filho e do Filho ao Pai: o Pai envia ao Filho o seu próprio Espírito, aquele que o ressuscita dos mortos. A morte de cruz se manifesta como o lugar da oferenda total do Filho ao Pai e origem da revelação que tem o seu ponto ápice na ressurreição de Jesus e no Pentecostes (MOINGT, 2008a, p. 67).

A ressurreição fez Cristo entrar numa dimensão humana universal, tornando-o irmão de todos, o Primogênito de uma nova raça (MOINGT, 2010a, p. 339), que supera qualquer divisão herdada da carne, sendo o homem novo (Ef 2,15; $\mathrm{Cl} 3,10$ ), capaz de uma relação pessoal com o ser humano $(\mathrm{Gl} 2,20)$. O cumprimento da salvação tem seu lugar próprio não na paixão e na morte de Jesus, mas na sua ressurreição, que é a abertura da vida eterna a que o projeto criador chama todos os homens e que o Espírito Santo difunde no coração do mundo (MOINGT, 2010b, p. 357).

Na Ressurreição, Cristo acolhe a existência infinita do Verbo como uma força de vida ilimitada, recebe um poder libertador que tem a capacidade de tirar toda servidão. Recebe a sua consciência de Filho, nosso irmão, abertura para que a história se encaminhe para uma comunhão universal. Tudo que aconteceu na história de Jesus de Nazaré, todos os enfrentamentos de seus limites humanos, vencidos no amor são conferidos: "o Filho confere a ele [o Verbo] a capacidade de transcender a sua finitude, tornando-se comunicável a todos, libertador de todos, vivificante para todos" (MOINGT, 1967, p. 217). Nesta linha, Moingt considera que a ressurreição é misteriosa, não é um fato que se possa reconstituir pela 
linguagem, mas a narrativa nos dá condições de afirmar que se trata de um encontro, de uma comunicação intersubjetiva que religa os discípulos que estiveram separados de Jesus depois de sua morte (MOINGT, 2008b, p. 321).

A ressurreição inaugura a etapa do envio do Espírito. Este não é uma pessoa como o Eu do Pai que diz o Tu do Filho. Ele é pessoa no modo de existir no Pai e no Filho, "a alteridade de cada um no outro e a identidade comum de ambos” (MOINGT, 2008b, p. 526). A morte, a ressurreição e o envio do Espírito são uma unidade que revelam que Jesus entra em Deus na plenitude de sua pessoa de Filho e adquire o poder de comunicar aos outros a santidade divina, cumprindo sua vocação de alteridade. Há, pois, uma entrada do Filho e uma saída divina pelo Espírito que agora comunica o ser divino, um dom ao ser humano: o ser-amor de Deus sob o seu modo próprio de ser, ou seja, o doar-se de si (MOINGT, 2008b, p. 526). Há, portanto, uma força que sai de Cristo e vai ao encontro com o ser humano. O Espírito é a expressão de amor e de vida que sai do Filho, como se ele não pudesse conter-se dentro de si, saindo para arrastar todos para Ele, para que vivam em sua comunhão com o Pai, em sua comunhão de alteridades, comunhão intersubjetiva e pluripessoal.

\section{Comum e comunicável - 0 Espírito em vistas da plenitude}

Como vimos na trinitologia de Moingt, existe um mistério de entrega divina que se revela na morte e ressurreição de Jesus, e que seria incompleta sem o dom do Espírito. "O dom não se impõe: pede e espera ser recebido, e o doador nada toma do donatário, mas só aceita receber dele, ele se dá" (MOINGT, 2010b, p. 351). Porém, não pode haver uma desigualdade entre o doador e o beneficiário. Por isso, Deus mesmo se dá, se faz um outro si mesmo em Jesus. É desta troca recíproca de amor entre o Pai e o Filho que procede o Espírito (MOINGT, 2010b, p. 92).

Neste sentido, pode-se adjetivar o Espírito Santo como um ser comum e comunicável: é comum a Cristo e ao Pai e comunicável a todas as criaturas por intermédio de Cristo. O derramamento do Espírito sobre toda carne (At 2,17) é sinal da alteridade de Deus, realizando as profecias 
do Antigo Testamento ( $\mathrm{J} 13,1$; Is 32,15 ) e introduzindo as criaturas na intimidade de Deus ( $\mathrm{Rm}$ 8,15-16). Moingt adverte que tal intimidade foi fator de blasfêmia (Jo 10,31-36): “Deus se 'profana' tornando-se 'comum”" (MOINGT, 2008b, p. 335). Sua profanação ou laicização concretiza-se como um derramar-se sobre toda carne: Deus se comunica e realiza o Cristo (MOINGT, 2010a, p. 429-434). Deus dá o seu Espírito para que seja infundido no ser humano o amor, fazendo-o Filho adotivo do Pai. Pelo Espírito todos serão revestidos como uma pessoa comum, um mesmo corpo, uma pluralidade de pessoas em unidade com Deus (MOINGT, 1967, p. 218-219).

O envio do Espírito pelo Pai e pelo Filho coincide com o envio dos apóstolos ao mundo (Jo 20,21-22). Ele continua vivendo sob muitas formas na vida dos fiéis, vive em todos e em cada um deles ao mesmo tempo. Por isso, a expressão paulina corpo de Cristo não é uma mera metáfora, mas manifesta uma realidade: o Ressuscitado traz vida aos seres humanos, pela fé nele, reúne todos em seu corpo ressuscitado ( $\mathrm{Rm} 8,11$; 1 Cor 12,27). A encarnação se estende por toda a humanidade, é universalizada, efetivando a presença de Cristo, uma presença invisível na ação da Igreja. Mas nem a presença e nem a ação do Espírito são limitadas à Igreja: o Espírito é a respiração, é o sopro, traz o Verbo da Vida até os confins da terra em todos os lugares e em diversos modos (MOINGT, 1967, p. 218-219; MOINGT, 2008b, p. 331).

O Verbo se afasta do Pai para ser outro e se torna estranho a ele. Há um distanciamento necessário. Nesta distância infinita não há um vazio, pois o Espírito preenche este espaço. O Pai encontra a sua glória em contemplar-se no Verbo. O Pai deseja que o Verbo faça advir a sua imagem nos seres criados para torná-los participantes de sua vida. Há um desejo comum do Verbo e do Pai neste intento, que se exprime no dom do Espírito Santo - laço entre toda criação, o Pai e o Verbo, o ser que realiza a unidade na alteridade (MOINGT, 2010b, p. 238-239).

Assim, Deus não criou o Universo e se afastou dele, mas se manifesta em sua presença misteriosa no processo evolutivo, que caminha sempre para formas mais complexas. Deus age com suas duas mãos, como nos diz Santo Irineu: "é permitido dizer que Deus pôs a mão na massa, e mesmo as duas mãos, o Verbo e o Espírito” (MOINGT, 2010b, p. 170). 
Com a mão do Verbo e com a mão do Espírito, o Espírito age para que haja coesão no universo, para que tudo se unifique até que tudo seja recapitulado em Cristo: o Espírito molda o mundo para que atinja a imagem do Filho (MOINGT, 2010b, p. 170-171; p. 242).

Seguindo o pensamento patrístico, Moingt defende que a salvação está vinculada à encarnação que, por sua vez, une-se à criação. A história universal caminha para uma humanização total em Cristo - "da hominização à humanização” (MOINGT, 2012, p. 156). Desde as origens, Deus nos sonhou em Cristo para que se realize o plano salvífico (Ef 1,4), por isso "Cristo é o primogênito de toda criatura" $(\mathrm{Cl} 1,15)$. Nesta visão unitária, que une criação, encarnação, salvação, Cristo não tem o seu sentido numa mera vinculação ao pecado, mas de um modo muito mais sublime. Ele é o sentido de toda a obra da criação, o protótipo de toda a humanidade, como Adão era o protótipo histórico, pois ele é a meta para o qual toda a humanidade caminha atraída pela força divina até que seja o pleroma (plenificação): o Cristo encarnado, morto e ressuscitado é o centro do Universo; Ele é o "Alfa e o Ômega, o Princípio e o Fim” (Ap 21,6), pois tudo o que existe converge para estar unido nele (MOINGT, 2012, p. 546-548).

O Pai ama o dessemelhante (a criação), desejando que o mesmo seja elevado à semelhança do seu Verbo pela participação do Espírito, que é Espírito de amor (MOINGT, 2010b, p. 319-320). Esta imagem divina impressa na história é o sim de Deus a sua criação: o Verbo é o sim de Deus à criatura (MOINGT, 2001, p. 148): o Verbo diz o seu sim ao Pai, respondendo a sua interpelação. Pelo sim do Verbo tudo veio a existir, sendo chamado a receber a adoção filial (dos homens). Unindo-se aos seres humanos, ao mundo, faz a carne do mundo ser semelhante a Deus, que agora deverá ser elevado à plenitude de Deus. Deus veio e não voltou, veio para ali permanecer, para fixar o seu ser aí, mas de algum modo já estava. Comunicando o seu ser pessoal ao homem que é Deus humanizado, o mundo e todos os seres humanos agora poderão passar da morte à vida eterna (MOINGT, 2010b, p. 323).

Com efeito, desde aquele momento, Deus estava trabalhando no mundo e preparava a eclosão de sua imagem. Momento de eternidade: "desde" que o Pai concebe seu Verbo e nele contempla sua perfeita imagem, vê a 
possibilidade de reproduzi-la até o infinito, e deseja que isso seja, sabendo o quanto seu desejo torna bom tudo o que deseja: e desde que o Verbo o gratifica, em retorno, com o Sopro de amor exalado nele, o Pai o difunde sobre o tudo o que seu Verbo torna possível, e esse possível logo se anima e o olhar do Pai vê o quanto isso é bom e faz que seja. [...] O mesmo olhar do Pai que contempla em seu Verbo toda bondade possível que lhe fará aparecer de fora, em um "fora" que recebe, por razão de ser e por essencial bondade, a capacidade de conter uma coisa tão boa "para louvor de sua glória" (Ef 1,14) (MOINGT, 2010b, p. 168).

O Verbo e o Espírito continuam sempre em devir, não como uma presença difusa na matéria, mas em intercomunicação de alteridades, um processo de emergir a imagem divina (MOINGT, 2010b, p. 171). Porém, não se trata de uma processualidade contínua e tranquila ao rumar para o seu Ômega. É preciso considerar a impotência de Deus que se revela abaixando-se e suportando com paciência como uma mãe educa o seu filho. A ek-sistência divina se manifesta em ação misteriosa e kenótica. Deste modo, a atividade de Deus no curso da história segue sem apelar para outra potência criadora senão a do amor esvaziado que prefere a suavidade da presença do que os atos de poder, que se desenvolve ao longo de sucessivas mortes (MOINGT, 2008b, p. 503-506).

É neste sentido que Paulo nos fala que o mundo está em trabalho de parto $(\mathrm{Rm} 8,22)$, o que inclui a potência negativa do mal que não deseja que a obra chegue ao seu curso. Deus sofre a dor de gerar o seu Verbo, o Verbo sofre a dor de ser gerado no nada do ser humano, o Espírito de se esgotar com seu sopro criador. Neste caminho, ficam latentes as dores de parto do cosmos e o silêncio de Deus, que é muito mais percebido que a sua presença. Há a tentação de censurar Deus por isto, diante dos caminhos dolorosos da história: o acolhimento desta pedagogia divina será sempre um desafio, implica uma abertura de total confiança, pois não estamos privados do mal, sobretudo das equivocadas escolhas humanas. Deus, no entanto, apesar do seu silêncio diante do mal, nunca deixa de vigiar e dar o seu consolo (MOINGT, 2010b, p. 262-263).

$\mathrm{Na}$ dinâmica da esperança escatológica, o ponto auge da economia divina descrita por Moingt é a ressurreição de todos, unidos em um Corpo, como nos revela a teologia de São Paulo (Rm 8,11; 1Cor 12,13). 
Irá se formar como que um único ser, todos vivendo na relação, na ligação de uns com os outros, e todos unidos a Cristo, pois tal ligação não é destruída com a morte, mas potencializada e plenificada no auge da história. Permanece nossa corporeidade, mas agora transformada em um nó de relações articuladas, um corpo coletivo. A ressurreição, na dimensão do futuro, é a cooperação invisível entre mortos e vivos que o símbolo da fé chama de comunhão dos santos, realidade já existente no tempo, mas toda plena escatologicamente (MOINGT, 2005, p. 519-523).

Há uma ação divina que impele para que os seres criados se atraiam, se reúnam, quando tudo for recapitulado em Cristo Jesus, o Primogênito de toda a criação. Mas não realiza tal intento anulando as individualidades, mas construindo um grande corpo intersubjetivo - uma comunhão de alteridades. Cada indivíduo, no entanto, não se fecha em si, mas se abre ao outro. Assim, o próprio Filho que se comunica e atrai a todos para a sua plenitude não se contenta em ser um indivíduo particular, mas Ele é tudo o que falta em cada indivíduo, tudo o que falta para que cada um tenha a sua plenitude. Ao unir-se nele, pode então realizar o seu acabamento (MOINGT, 1967, p.221-222; MOINGT, 2014, p. 563-576). O Espírito lança no universo o apelo à liberdade do amor, que se infiltra através da separação das espécies e da atração mútua dos corpos diferentemente sexuados e que terminará um dia por exprimir-se na tomada de consciência de que o outro é outro, desejável, mas inviolável, digno de ser amado por si mesmo (MOINGT, 2010b, p. 171).

Moingt retoma o pensamento escatológico de Teilhard de Chardin (1995, p. 279-336), autor francês que foi inovador na conciliação entre o pensamento evolutivo e o cristianismo. Este pensa a ressurreição dentro de um projeto divino integrador, no qual o indivíduo terá sua plenitude na unidade de todos os seres humanos em Deus, bem como do cosmos, ou seja, não somente haverá uma comunhão dos indivíduos, mas de toda a criação. O Universo ilumina a imortalidade de Cristo. Cristo é considerado em sua radicalidade como primogênito de toda a criação, em quem tudo se mantém $(\mathrm{Cl} 1,17)$, como modelo cosmológico do mundo que virá (MOINGT, 2012, p. 550). Deus será tudo em todos (1Cor 15,28; Ef 1,23, $\mathrm{Cl} 3$,11). Em Cristo se dá a recapitulação de tudo o que existe, a união das coisas visíveis e invisíveis, o Pleroma é o corpo de uma multidão de coisas 
e indivíduos. Se toda criação gemia em trabalho de parto ( $\mathrm{Rm} 8,22)$, agora há a sua plenitude em Cristo $(C l 1,16.19)$. Nós seremos plenamente o Corpo de Cristo como já era prefiguração a comunhão eucarística (1Cor 12,12-14.27) (MOINGT, 2012, p. 564).

No fim, haverá, por assim dizer, a realização plena da Trindade econômica. O Paráclito, o terceiro que media o diálogo entre o Pai e o Filho, que realiza o nós definitivo, quando a criação se une à Trindade, formada na imagem do Verbo, realização do projeto primordial do Pai. Então podemos dizer que de fato a Trindade Eterna é a Trindade Econômica, não numa comunhão puramente divina, mas numa comunhão inter-relacional que inclui a humanidade e o Universo resgatados (MOINGT, 2012, p. 556-558).

\section{Espírito de liberdade}

São Paulo afirma que pertence a Deus quem tem o "Espírito de Cristo" (Rm 8,9). Este atributo peculiar dado ao Espírito o qualifica a partir de sua relação com a história de Jesus: na encarnação, o Espírito Santo não ficou isento da kenosis, pois quando o Verbo se encarna, o Espírito se humaniza: mistura-se com o espírito de Jesus, experimentando assim a condição finita que é a nossa. Quando Cristo retorna ao Pai, o Espírito dele sai para cumprir sua missão, assumindo agora o caráter de Espírito de Cristo, ou seja, o Espírito que procede de Cristo, assim como procede do Pai. Agora o Espírito é Espírito de um homem, difundido por toda humanidade (MOINGT, 2010b, p. 361; p. 366).

Se temos o Espírito de Cristo, temos um Espírito de Liberdade: "O Senhor é o Espírito e onde está o Espírito, ali está a liberdade" (2Cor 3,17) (MOINGT, 2010b, p. 346). É preciso considerar que antes de ser o Espírito de Cristo, Ele foi o Espírito de Jesus histórico, conduzindo-o sempre à liberdade. A força do Espírito em Jesus o faz ter uma relação de liberdade com o Pai, fazendo-lhe aderir à sua vontade. $\mathrm{Na}$ agonia do Getsêmani, compreendemos que Jesus não realiza a própria vontade, mas a vontade do Pai. O não de Jesus inverte-se no sim eterno pronunciado 
pelo Pai, ação esta que não foi realizada sem a presença do Espírito, que aparece na Escritura em atuações pontuais na vida de Jesus.

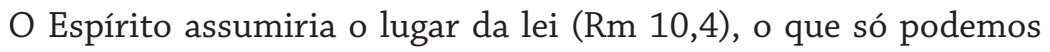
compreender no horizonte da liberdade de Jesus. Ele veio para dar pleno cumprimento da lei (Mt 5,17), mas realizou tal pretensão muito distante de um zelador da lei, de alguém inclinado a cumprir os preceitos. Jesus ensinou o que agrada a Deus, prescindindo da palavra da lei, da classificação dos pecados, das listas de sanções e penalidades. Ensinou que a impureza é o que sai do coração do homem (Mt 15,19-20) e que o sábado foi feito para o homem e não o contrário (Mc 2,27-28). Enfim, Jesus relativizou a lei e mostrou os limites da religião, que deveria escapar da tutela rigorista dos mestres religiosos. Estes últimos consideravam o ensinamento de Jesus um ultraje e, por isso, desejavam que ele não exercesse influência sobre as pessoas (MOINGT, 2008b, p. 404-409).

O templo é igualmente relativizado (MOINGT, 2008b, p. 432-441). Jesus expulsa os vendilhões do templo, diz que será destruído e será construído em três dias, causando a fúria dos mestres religiosos. Inaugura um culto em espírito e verdade: não porque desejasse uma religião sem ritualidade como interpretaram os pensadores das luzes, mas porque retira do culto judaico e dos samaritanos o poder de domínio e fascinação. Agora Deus se manifesta no corpo sofredor e libertado do sofrimento, o Deus humanizado, novo templo. Ao se aproximar da mulher impura (Jo 4,9), já se torna sinal do novo culto que não olha para a lei, mas para o espírito. Aliás, seu sinal distintivo foi se aproximar, fazer-se próximo, irmão de cada pessoa, eliminando qualquer barreira que impedia a comunicação entre as pessoas, abolindo as leis religiosas que separam puros e impuros, pois a alteridade é o lugar onde Deus fez sua habitação (MOINGT, 2008b, p. 416).

O Espírito de Cristo é agora o Espírito em nós. Portanto, somos chamados à mesma liberdade, a ser sujeito da história, isso é salvação. Por isso, Deus se limita em sua potência, porque respeita a nossa liberdade. Ele deseja que o ser humano livre aprenda a vencer os limites da história, assumindo todos os aspectos de sua existência. Faz inclusive com que sua vontade fique entregue à história humana, às liberdades humanas, permitindo que o Filho de Deus esteja entregue em nossas mãos. A humanização 
de Deus, que limita a onipotência divina, revela ao ser humano que ele precisa fazer a sua parte, é livre e responsável pela sua existência, pela construção de sua história. "[O Espírito] deixa aos homens a liberdade de serem eles mesmos, sem medo e sem reprimenda, e de se amarem uns aos outros, sem obrigação de acréscimo" (MOINGT, 2008b, p. 527).

Deus derrama o seu Espírito sobre toda carne: faz com que nasçam filhos de Deus, filhos da liberdade. Por isso, os discípulos devem ir para além dos atos religiosos, indo até Deus em sua proximidade paternal, que capacita a intimidade. É preciso romper com as antigas representações, com os comportamentos e mentalidade do passado, para aprender quem é Deus em Jesus, realizando um verdadeiro nascimento, como nos ensina a perícope do diálogo com Nicodemos (Jo 3,3) (MOINGT, 2010a, p. 294). A intimidade com Deus não se realiza sob o horizonte das regras impostas, Jesus não nos dá garantias em troca de um preceituário seguido nas minúcias, não dá uma fórmula pronta para copiar, mas uma vida que ama na liberdade do Espírito:

[...] uma vida que se salva se perde, de uma liberdade que se afirma se nega, de um mandamento que resume todos os preceitos, mas se subtrai a toda medida de verificação, porque é todo um excesso, à imagem e à medida do amor trinitário (MOINGT, 2010b, p. 372).

O Espírito de Cristo em nós não faz imposição alguma. Seria contraditória uma liberdade que se impõe. Por isso, prorroga nossas dívidas, concede-nos perdão, não nos julga com o peso da autoridade. Deseja que vivamos o seu amor na liberdade, concede-nos o Espírito como dom, por isso há o risco de ignorarmos o próprio Deus. Ele aceita o risco, ao preferir esta dinâmica de gratuidade: "O Espírito não deixa de imprimir em nós a gratuidade da existência simbólica, revelando-nos que somos filhos de Deus (Rm 8,16)" (MOINGT, 2008b, p. 337). O Espírito de Cristo, gratuitamente nos concede seus dons, que nos impulsionam para viver a vida dele, para que nossa humanização se conecte em projeção de ser a humanização de Deus. 


\section{Considerações finais: 0 Espírito e a missão da Igreja}

É perceptível, na teologia de Moingt, a importância da relação entre Páscoa e Pentecostes, constituídos como um único acontecimento revelador da salvação. Jesus, em seu trabalho de liberdade, não foi passivo, mas lutou contra a morte. Sua luta não acabou na derrota, pois venceu a morte, escapou dela, pois o Pai acolheu a sua oferta, dando-lhe poder de ressurreição. Por sua vez, a ressurreição e o dom do Espírito Santo marcam a recriação de todas as coisas em Cristo (2Cor 5,17): o dom do Espírito faz o novo, transforma, muda, deseja dar a tudo a vitalidade do Ressuscitado, até a consumação.

Neste sentido, a pneumatologia de Moingt nos abre uma perspectiva missiológica. O Espírito age na Igreja em dois níveis: ad intra, renovando-a ao seu sabor; ad extra, impelindo os discípulos de Cristo para colaborar na realização consumadora que está em projeto de ser.

O Espírito é realizador da missão ad intra. A pneumatologia de Moingt enfatiza que o cristianismo é essencialmente uma religião do Espírito e, por isso, é a religião que traz a liberdade em Cristo ( $\mathrm{Rm} 8,15$; Gl 5,1). O Espírito tira a rigidez da instituição, devolve o frescor, a leveza. Uma Igreja do Espírito, portanto, é uma Igreja que caminha livre, sem amarras, sem pesos, sem absolutizar a autodefesa.

Ao longo da história, percebermos que a Igreja, muitas vezes, adotou as práticas criticadas por Jesus, trazendo de novo a lei da servidão, do medo, da culpa, da angústia gerada pela salvação meritória. Moingt, repetidas vezes em seus escritos, repete uma afirmação de Bonhoeffer, que aqui parece oportuno retomar: o convite divino à liberdade é tão radical, que Deus prefere o ser humano longe das amarras da religião, se esta privá-lo de ser livre (LESEGRETAIN, 2012). Trata-se de uma afirmação radical, mas necessária aos nossos tempos, pois testemunhamos muitas visões retrospectivas que apontam para um enrijecimento institucional arraigado em bandeiras do passado como uma espécie de tábua de salvação diante dos desafios do tempo. A Igreja jamais poderá ser o lugar da servidão, muito menos escrava de si mesma. Por isso, deverá ser dócil à condução do Espírito de liberdade que habitou Jesus de Nazaré — homem livre e libertador. 
O Espírito é realizador da missão ad extra. Deus nos concede um Espírito de amor e liberdade (MOINGT, 2016, p. 356-359), portanto, dóceis ao mesmo Espírito, os discípulos de Cristo recebem a tarefa de semear a comunhão das alteridades. Trata-se de uma fidelidade ao Espírito que une, aquela mesma força que desfez a desagregação de Babel ao promover a comunhão de uma diversidade de povos na compreensão uníssona da proclamação das maravilhas de Deus (At 2,11). Também a fidelidade se remete ao impulso do Espírito que move a história para uma comunhão universal, como tratamos acima. Este Espírito não é propriedade de uma instituição, mas aquele que dissemina a presença salvífica de Cristo por toda a terra, sem barreiras institucionais - "o vento sopra onde quer" (Jo 3,8). Em meio a pluralidade, marca deste momento histórico, vemos emergir sectarismos, afirmações de identidades que promovem lutas, ao invés de diálogo. Parece que, em alguns âmbitos, o diferente é o inimigo, não o judeu caído à beira da estrada à espera de curativos. É preciso, neste contexto, reafirmar que o Espírito Santo é comunicável para unir o que está dividido. Sua ação no mundo jamais cessa, sempre desperta vozes e posturas livres que deixam as amarras de qualquer instituição em nome do amor, gerador de compreensão, diálogo e unidade. O Espírito é o terceiro que une os dois primeiros e é comunicável à criatura a fim de que a relação do eu-tu seja geradora de um nós - comunhão.

\section{Referências}

LESEGRETAIN, C. Joseph Moingt, l'appel pressant d'un théologien. Lacroix, n. 245, p. 19, 2012.

LÉVINAS, E. Totalidade e infinito. Trad. João Gama. Lisboa: Edições 70, 1982.

MERLEAU-PONTY, M. Em toda e em nenhuma parte. In: CHAUÍ, M. (seleção). São Paulo: Abril Cultural, 1975. (Os Pensadores, v. 16).

MOINGT, J. Universalité de Jésus-Christ. Tome 4. Revue de théologie et de philosophie, 1967. 
MOINGT, J. Les Trois Visiteurs: entretiens sur la Trinité. Paris: Desclée de Brouwer, 1999.

MOINGT, J. Imagens, ícones e ídolos de Deus: a questão da verdade da teologia cristã. Revista Concilium, Petrópolis, n. 289, 2001.

MOINGT, J. El Espíritu Santo: el tercero. Selecciones de Teología, v. 42, n. 168, 2003.

MOINGT, J. S'éveiller à la Résurrection. Tome 402. Études, 2005/6, 2005.

MOINGT, J. L'Évangile de la réssurrection: méditations spirituelles. Paris: Bayard, 2008a.

MOINGT, J. O homem que vinha de Deus. São Paulo: Loyola, 2008b.

MOINGT, J. Deus que vem ao homem. Do luto à revelação de Deus. v. I. São Paulo: Loyola, 2010a.

MOINGT, J. Deus que vem ao homem. Da aparição ao nascimento de Deus. v. II Aparição. São Paulo: Loyola, 2010b.

MOINGT, J. Deus que vem ao homem. Da aparição ao nascimento de Deus. V. II Nascimento. São Paulo: Loyola, 2012.

MOINGT, J. Croire au Dieu qui vient. Tome I - de la croyance à la foi critique. Paris: Gallimard, 2014.

MOINGT, J. Croire au Dieu qui vient. Tome II - Esprit, Eglise et monde : de la foi critique à la foi qui agit. Paris: Gallimard, 2016.

TEILHARD DE CHARDIN, P. O fenômeno humano. São Paulo: Cultrix, 1995.

Recebido: 29/11/2018

Received: 11/29/2018

Aprovado: 27/03/2019

Approved: 03/27/2019 